\title{
Satellite derived precipitation and freshwater flux variability and its dependence on the North Atlantic Oscillation
}

\author{
By AXEL ANDERSSON ${ }^{1 *}$, STEPHAN BAKAN ${ }^{2}$ and HARTMUT GRAßL ${ }^{1}, \quad{ }^{1}$ Meteorologisches \\ Institut der Universität Hamburg, Hamburg, Germany; ${ }^{2}$ Max-Planck Institut für Meteorologie, \\ Hamburg, Germany
}

(Manuscript received 7 August 2009; in final form 9 April 2010)

\begin{abstract}
The variability of satellite retrieved precipitation and freshwater flux from the 'Hamburg Ocean Atmosphere Parameters and Fluxes from Satellite Data' (HOAPS) is assessed with special emphasis on the 'North Atlantic Oscillation' (NAO). To cover also land areas, a novel combination of the satellite derived precipitation climatology with the rain gauge based 'Full Data Reanalysis Product Version 4', of the 'Global Precipitation Climatology Centre' (GPCC) is used. This yields unique high-resolution, quasi-global precipitation fields compiled from two independent data sources. Over the ocean, the response of the freshwater balance and the related parameters to the NAO is investigated for the first time by using a purely satellite based data set.

A strong dependence of precipitation patterns to the state of the NAO is found. On synoptic scale this is in accordance with earlier findings by other satellite based and reanalysis products. Furthermore, the consistency of the combined HOAPS-3/GPCC data set allows also detailed regional analyses of precipitation patterns. The response of HOAPS-3 freshwater flux to the NAO is dominated by precipitation at mid and high latitudes, while for the subtropical regions the feedback of the evaporation is stronger.
\end{abstract}

\section{Introduction}

Despite their climatological importance, precipitation and freshwater fluxes over the global oceans have not been known well enough for long, mainly due to various difficulties with in situ measurements. Only recently, the availability of passive microwave detectors on satellite platforms in space allows the retrieval of these important water cycle components over the global ocean with useful sampling and measurement accuracy.

The Hamburg Ocean Atmosphere Parameters and Fluxes from Satellite (HOAPS) data set, uses such microwave satellite data to provide fields of precipitation and evaporation over the global ice free ocean between 1987 and 2005 (Andersson et al., 2007; Andersson, 2009). Special emphasis has been put into quality control and intersatellite calibration in order to arrive at acceptable temporal and spatial consistency of the data fields without employing additional model or reanalysis input. This data set has been developed to its present state within the scientific context of the DFG funded Collaborative Research Center 512 at the

\footnotetext{
* Corresponding author.

e-mail: axel.andersson@zmaw.de

DOI: $10.1111 /$ j.1600-0870.2010.00458.x
}

University of Hamburg on 'Cyclones and the North Atlantic Climate System'. This paper contains first results of the application of HOAPS data towards a better knowledge of the water cycle components in connection with the North Atlantic Oscillation (NAO), a major topic of interest within the mentioned research incentive.

The NAO is one of the most prominent atmospheric teleconnection patterns of the Northern Hemisphere with distinct impacts for the whole oceanic and continental North Atlantic region. Especially for the European winter, the climatic conditions are to a great extent determined by the NAO. Hence, a detailed description and assessment of related quantities is of high relevance. Therefore, the variability of essential HOAPS-3 parameters with special emphasis on the NAO will be investigated. While the main focus of this study is on precipitation, the freshwater flux and related parameters will also be examined.

This study follows a novel approach by combining over-ocean satellite retrievals with a purely rain gauge based land data set. Over the ocean satellite retrievals of precipitation are generally more reliable than over land. In the microwave spectrum the ocean surface provides a relative homogeneous radiometrically cold and polarized background signal from which the precipitation is clearly distinguishable due to the unpolarized emission 
from rain and scattering signatures of ice particles. Over land these assumptions do not hold true because the emissivity of the land surface is highly variable. This impairs in particular the retrieval of the emission signal from rain. In order to avoid these complications, HOAPS-3 does not include any overland precipitation retrievals in the current version. Hence, HOAPS-3 was complemented with the 'Full Data Reanalysis Product Version 4' (Schneider et al., 2008), which is provided by the Global Precipitation Climatology Centre (GPCC). This product is solely based on rain gauge measurements and provides nearglobal land surface precipitation. The combination of both data sets yields unique high-resolution and quasi-global precipitation fields compiled from two independent data sources.

Other satellite climatologies, such as the Global Precipitation Climatology Project (GPCP, Adler et al., 2003), NOAA's Climate Prediction Center (CPC) Merged Analysis of Precipitation (CMAP, Xie and Arkin, 1997), or products from the Tropical Rainfall Measuring Mission (TRMM, Adler et al., 2000) provide over land retrieved precipitation data. However, in order to correct the deficiencies in the satellite retrievals, these satellitebased estimates are constrained or complemented with precipitation data from rain gauge measurements. The CMAP enhanced data set (Xie and Arkin, 1997) additionally uses reanalysis data.

Next to precipitation, the ocean surface freshwater flux plays an important role for the North Atlantic climate system. Variations of this parameter over the ocean are considered large enough to influence surface salinity with the potential to affect the thermohaline circulation in the ocean (Marshall et al., 2001; Hurrell et al., 2003).

A previous analysis based on the first version of HOAPS by Bakan et al. (2000) for the two winter seasons of 1994/1995 and 1995/1996, which represented a pronounced high and low NAO state, indicated the potential of satellite derived data to assess the variability of over-ocean freshwater flux components. However, this case study lacked a sound statistical basis. Recently Mariotti and Arkin (2007) assessed the long-term sensitivity of oceanic precipitation to the NAO using reanalysis data and the satellite based CMAP and GPCP products. Many other studies featured either only land based precipitation, used ship based measurements or were exclusively based on model and reanalysis data (e.g. Cayan, 1992b; Hurrell, 1995a; Walsh and Portis, 1999; Bojariu and Reverdin, 2002). More information on previous studies concerning the NAO can be found in the review by Wanner et al. (2001).

Complementing the analysis of North Atlantic variability presented in this study, a qualitative assessment of systematic uncertainties in modern freshwater flux estimates including HOAPS-3, NCEP, and the adjoint ocean circulation model German ECCO (GECCO) is given in Romanova et al. (2010) in this special issue. For the North Atlantic region, Romanova et al. (2010) show that the GECCO model often corrects away from the NCEP first guess data towards the HOAPS- 3 estimates.
This paper is structured as follows. After an overview of the NAO, Section 3 contains an introduction to the data bases used in this study. Impacts of the NAO on regional precipitation will be presented in Section 4, followed by the evaluation of the cold season response of precipitation and freshwater flux parameters to the NAO. Composite fields are evaluated in Section 5. Correlation patterns for the precipitation with the NAO index on a global scale are compared for several data sets in Section 6. Finally, the response of HOAPS-3 North Atlantic freshwater flux parameters to the NAO are investigated in Section 7.

\section{The North Atlantic Oscillation}

Especially during the cold season, a pressure dipole associated with the Icelandic low and the Azores high is the dominant mode of weather and climate variability in the North Atlantic region. During this season, more than one third of the sea level pressure (SLP) variance over the North Atlantic can be attributed to the NAO (Barnston and Livezey, 1987; Hurrell and van Loon, 1997).

Because of its well-defined regional signature, the NAO can be described by the difference of the SLP at two stations near the centres of action. The first definition of such a 'North Atlantic Oscillation Index' originates from Sir Gilbert Walker (Walker, 1923; Walker and Bliss, 1932). Later, several commonly used station based NAO indices were defined by Rogers (1984), Hurrell (1995b) and Jones et al. (1997). These indices are computed from the normalized SLP difference between the Icelandic stations and Ponta Delgada on the Azores, Lisbon or Gibraltar. Another way of defining a NAO index is based on a rotated principal component analysis (RPCA) as proposed by Barnston and Livezey (1987).

In this study, the station based NAO index after Jones et al. (1997) is used, which is computed from the difference between the normalized SLP over Gibraltar and southwest Iceland (Reykjavik). The normalization is done on a monthly basis with long term means and standard deviations derived from the period 1951-1980. For the winter seasons, an index based on stations from the Iberian peninsula yields a slightly higher signal-tonoise ratio (Hurrell and van Loon, 1997; Jones et al., 1997) compared to an index based on the Azores-Iceland relationship.

The NAO index defines 'high' (positive) and 'low' (negative) states of the NAO depending on the meridional pressure gradient between the Azores high and the Icelandic low. The variations of this dipole pressure system causes impacts throughout the whole North Atlantic region. During positive NAO conditions $(\mathrm{NAO}+)$ the Icelandic low and Azores high are strengthened, creating an increased pressure gradient over the North Atlantic. As a consequence, the Westerlies are stronger and advect relatively mild and moist air to northern Europe while the eastern Canadian Arctic and the Mediterranean region experience dryer and colder conditions. Also the subtropical Easterlies are enhanced by the Azores high and cause mild to warm conditions in the southeastern United States (US). 
Phases in which the NAO index is negative (NAO-) are characterized by a weak Icelandic low and Azores high, which results in a decreased pressure gradient and the Westerlies slacken. The storm activity over the North Atlantic is decreased and the storm track is shifted southward, advecting more moist air to the Mediterranean region. Greenland also experiences mild weather, while northern Europe and the eastern US face cold conditions.

\section{Data bases}

For this study, a combined data set of satellite retrieved precipitation from the HOAPS-3 climatology and rain gauge based data from the GPCC was compiled. Both data sets stem from completely independent data sources and the combined HOAPS-3/GPCC product contains no adjustments between the data sets.

\subsection{HOAPS-3}

The HOAPS climatology derives the freshwater flux over the global ice free ocean entirely from satellite data. The current version, HOAPS-3, utilizes data from the Special Sensor Microwave Imager (SSM/I) operating on the polar orbiting Defense Meteorological Satellite Program (DMSP) satellites to retrieve the precipitation and basic state variables from which individual components of surface fluxes of heat and evaporation are derived. A detailed description of the methodology to derive these parameters is given in Andersson (2009).

Because of the specific goal of HOAPS to derive the global ocean freshwater flux continuously from satellite based data, great care was put into intersensor-calibration from different satellites for a homogeneous and reliable spatial and temporal coverage. Next to the parameters derived from brightness temperatures of the SSM/I radiometers, additional SST information for the retrieval of the latent and sensible heat flux parameters is taken from the NODC/RSMAS Pathfinder Version 5.0 data set (Casey, 2004; NODC, 2008) that is based on advanced very high resolution radiometer (AVHHR) measurements. As sea ice covered regions have to be excluded from the retrievals, a procedure to detect such scenes based on the NASA Team algorithm (Swift et al., 1985) has been implemented.

The HOAPS- 3 evaporation retrieval uses the bulk aerodynamic approach of the COARE 2.6a algorithm (Fairall et al., 1996, 2003). All relevant input parameters for this procedure, wind speed, surface atmospheric specific humidity, and sea surface saturation specific humidity, are derived from satellite based measurements, while the bulk transfer coefficient is parametrized with the COARE algorithm (cf. Andersson, 2009). The near surface wind speed is retrieved using a neural network which was trained with a composite of buoy match ups and radiative transfer calculations. A linear relationship of Bentamy et al. (2003) which is derived from a two-step regression method based on a set of collocated SSM/I brightness temperatures and ship measurements is used to estimate the near surface atmospheric specific humidity. The sea surface saturation specific humidity is calculated from the AVHRR SST measurements using the Magnus formula (Murray, 1967) and a constant salinity correction factor of 0.98 .

Similar to the wind speed retrieval, the HOAPS precipitation algorithm is based on a neural net approach. The neural network was trained with a data set of assimilated SSM/I brightness temperatures and the corresponding precipitation values of the European Centre for Medium-Range Weather Forecast (ECMWF) model. The resulting retrieval algorithm is independent of any ancillary information and relies exclusively on SSM/I brightness temperatures.

HOAPS data sets can be obtained from the website www.hoaps.org and currently cover the time period between mid 1987 and the end of 2005. In this study the HOAPS-3 monthly mean gridded product, HOAPS-G, with a resolution of $0.5^{\circ}$ is used (Andersson et al., 2007). Data from winter 1987/1988 are not used in this study due to a defective satellite radiometer (cf. Andersson, 2009). In addition to the publicly available data, the record for the precipitation parameter has been extended to April 2007 for this study and now includes nineteen December to March winter seasons from December 1988 to March 2007.

\section{2. $G P C C$}

To complement the HOAPS-3 oceanic precipitation with land data, rain gauge based data from the GPCC is used. All data that are processed at the GPCC stem from various sources of rain gauge raw data from international weather services and undergo various quality-checks, a meta data harmonization procedure, and are finally resampled as spatial means on a regular grid. As rain gauges are not distributed uniformly over the land surface, an empirical interpolation method is used to fill data void regions and to prevent overweights of clustered stations (Rudolf et al., 1994).

Several products are available from the GPCC. Here, the 'Full Data Reanalysis Product Version 4' (Schneider et al., 2008) with a grid resolution of $0.5^{\circ}$ is used for the combination with HOAPS-3. The time series starts with 1901 and is regularly updated with recent data. The Full Data Reanalysis Product uses all station data available in the GPCC data base to provide high spatial accuracy. A drawback of this procedure is that the number of stations per gridbox can vary, depending on the existing input data.

However, for the land areas surrounding the North Atlantic, the Full Data Reanalysis Product provides sufficient coverage throughout the overlapping time period with HOAPS-3. A dense coverage of stations is achieved, except for Russia, the almost data void Arctic, and desert regions in Africa and Arabia. As mentioned above, the temporal coverage of gauges is not constant and exhibits a continuous decline in the mean number of gauges per grid for the 1988-2007 period. Since this is mainly 

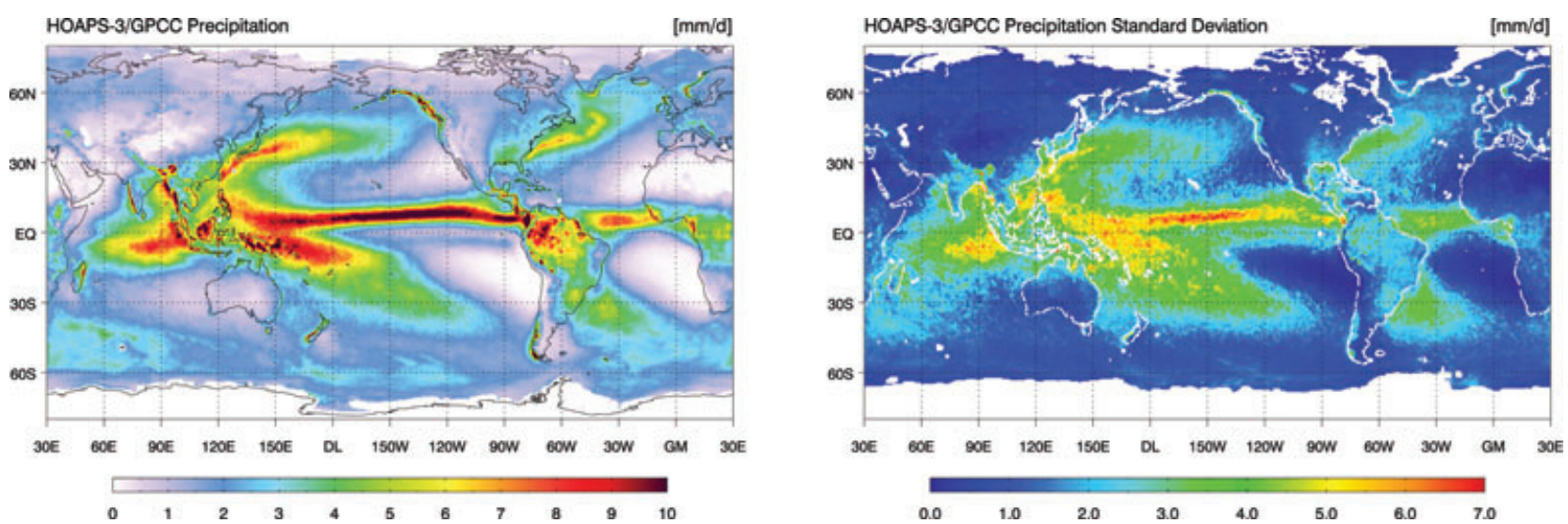

Fig. 1. Left-hand panel: global climate mean precipitation in $\mathrm{mm} \mathrm{d}^{-1}$ for the years $1988-2006$ of the combined HOAPS-3/GPCC product. Right-hand panel: Standard deviation of deseasonalized precipitation in $\mathrm{mm} \mathrm{d}^{-1}$ for the years 1988-2006 from the combined HOAPS-3/GPCC product. Coastline pixel, that are interpolated in the combined product have been left blank in the right-hand panel, as well as periodically sea ice covered regions.

caused by a decrease in the number of stations from central Europe and the United States and the number of stations is generally very dense in these regions, this decline does not affect the overall homogeneity of the product.

\subsection{Combined HOAPS-3/GPCC Product}

The GPCC Full Data Reanalysis Product and the HOAPS-3 monthly mean gridded data set are combined into a product with a grid resolution of $0.5^{\circ}$, which is available from both sources. Coastal pixels are not included in either of the data sets. Therefore, an interpolation routine was implemented to fill these gaps. The method involves a distance weighted mean of the 8 pixels surrounding the missing data point, while a minimum of five valid data points is the threshold for which the interpolation is performed. This procedure is repeated recursively until no gridboxes remain that fulfil the criterion for interpolation.

Overall, this yields a high-resolution data set, which is capable of resolving variability on fine spatial scales. The left-hand panel of Fig. 1 shows the climatological mean of the combined HOAPS-3/GPCC data set. Except for regions permanently covered by sea ice, the data void Antarctica and some smaller spots at islands or regions with very uneven coast lines, a quasi-global coverage is achieved. The resulting merged field is regionally consistent and exhibits apparently globally homogeneous precipitation structures. The transition of large-scale precipitation patterns from sea to land regions shows no jumps in magnitude and location.

Moreover, the variability of both data sets exhibits a good agreement in particular for the coastal transition zones, as shown in the local standard deviation of the deseasonalized precipitation (Fig. 1, right-hand panel). While the variability over land is small in particular for the desert regions as well as for mid and high latitudes, it is nearly as high as over the ocean in the tropics. Maxima, such as in the tropical Atlantic are resolved with comparable variability over land and ocean.

The following analyses will be limited to the land regions and the ice-free ocean, since no precipitation data over sea ice is available from either of the input data sets. During the Northern Hemisphere winter season, this concerns mainly the Arctic Ocean, the Nordic Seas and the Labrador Sea region.

For the correlation analyses in Sections 6 and 7 the data is locally deseasonalized and detrended for each gridbox in order to focus on the monthly variation of the data.

\section{Regional precipitation statistics}

As described in Section 2, some regions are distinctly impacted by the effects of the NAO. In the following the precipitation time series for the entire North Atlantic $\left(100^{\circ} \mathrm{W}-60^{\circ} \mathrm{E}\right.$, $20^{\circ} \mathrm{N}-80^{\circ} \mathrm{N}$ ) and for four selected regions as shown in Fig. 2

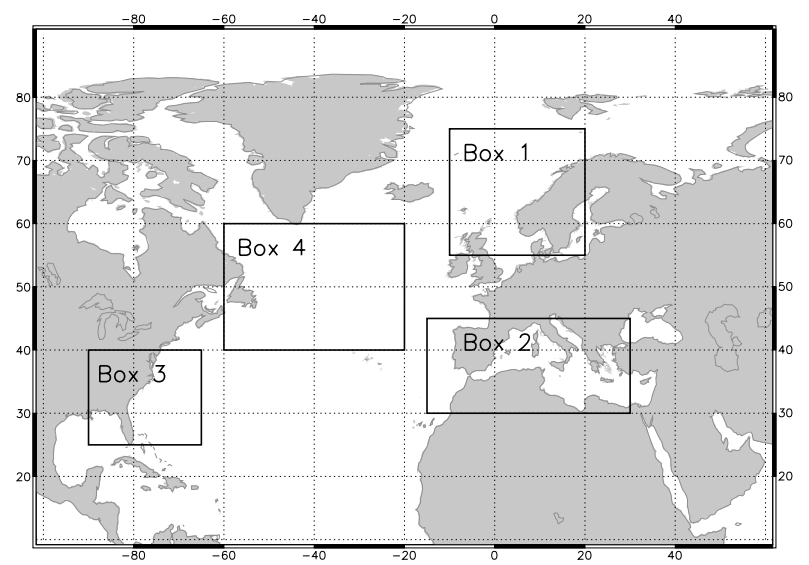

Fig. 2. Box areas for which spatial mean time series have been computed. 
are assessed. The selected regions are representative for northern Europe (Box $1,10^{\circ} \mathrm{W}-20^{\circ} \mathrm{E}, 55^{\circ} \mathrm{N}-75^{\circ} \mathrm{N}$ ), the western and central Mediterranean region (Box $\left.2,15^{\circ} \mathrm{W}-30^{\circ} \mathrm{E}, 30^{\circ} \mathrm{N}-45^{\circ} \mathrm{N}\right)$, the southeastern US including the Gulf Stream (Box $3,90^{\circ} \mathrm{W}-65^{\circ} \mathrm{W}$, $\left.25^{\circ} \mathrm{N}-40^{\circ} \mathrm{N}\right)$ and the storm track region of the central North Atlantic (Box $\left.4,60^{\circ} \mathrm{W}-20^{\circ} \mathrm{W}, 40^{\circ} \mathrm{N}-60^{\circ} \mathrm{N}\right)$.

Figure 3 shows the anomalies of the monthly mean precipitation relative to the climatological annual cycle for the period 1988-2006 for the spatial means of the entire North Atlantic domain and for each of the subregions. A three month running mean has been applied to the data, in order to filter high frequency fluctuations. In addition, the corresponding climatological annual cycle for each domain is depicted in the righthand panels of Fig. 3. The time series for the complete box, the land portion, and the oceanic part are depicted separately, while coastline pixels are treated as sea pixels. In Box 4 the small land part is neglected, and only the oceanic time series is shown. The monthly values of the NAO index are depicted into Fig. 3f.

Table 1 shows the correlation coefficients of the precipitation with the NAO index for each Box. The correlations were calculated for annual means and for the monthly values in the December to March winter seasons.

\subsection{Annual cycle}

The annual cycle (Fig. 3, right-hand panels) is more pronounced for the over-ocean precipitation compared to the overland values in all of the selected subregions. The peak in the seasonal cycle
Fig. 3. Deseasonalized precipitation time series of monthly spatial means and the corresponding mean annual cycle for boxes depicted in Fig. 2. A 3-month running mean filter has been applied to the data in order to filter high frequency fluctuations. Blue lines represent the mean for the oceanic part, red lines the mean for land part, and black lines the mean for the whole box. The small land part of Newfoundland contained in Box 4 is neglected, hence only the ocean part is plotted. Panel $f$ shows the monthly values of the NAO index after Jones et al. (1997). (a)

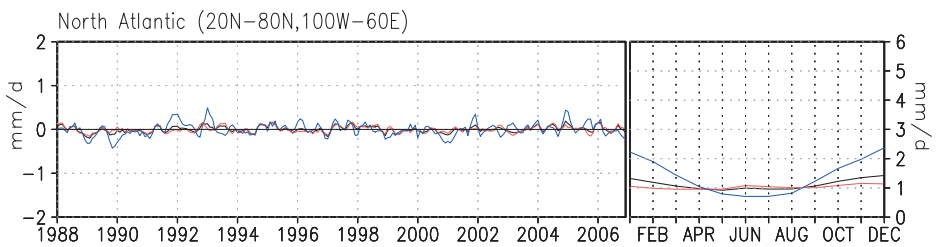

(b)

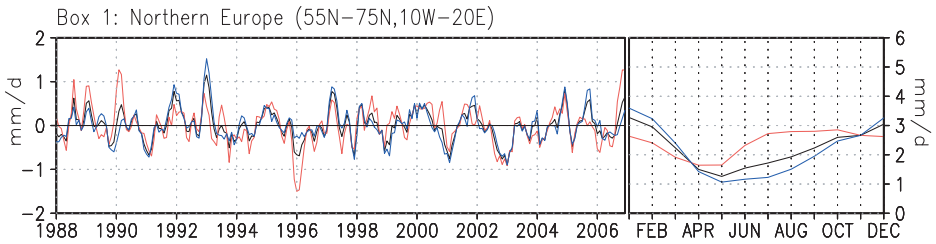

(c)

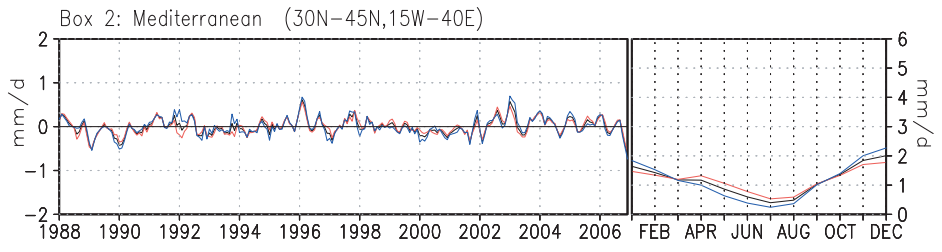

(d)

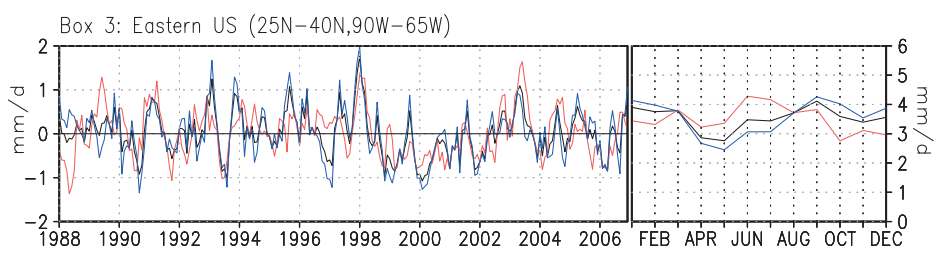

(e)

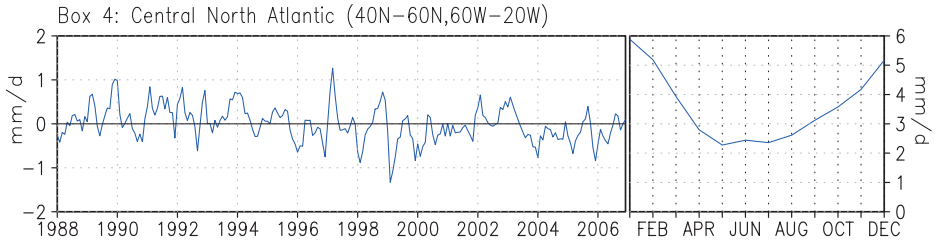

(f)

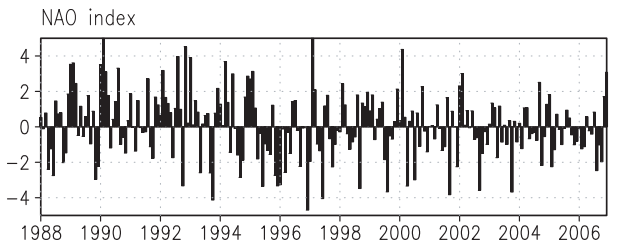


Table 1. Correlation coefficients of mean annual and winter (December-March) precipitation and the corresponding NAO index for the entire North Atlantic region and the subregions depicted in Fig. 3

\begin{tabular}{lrr}
\hline Region & $r$ annual & $r$ DJFM \\
\hline North Atlantic & $-0,18$ & $-0,17$ \\
Land & -0.03 & -0.04 \\
Sea & -0.31 & -0.25 \\
Box 1 & 0.46 & 0.62 \\
Land & 0.51 & 0.84 \\
Sea & 0.29 & 0.38 \\
Box 2 & -0.48 & -0.73 \\
Land & -0.46 & -0.74 \\
Sea & -0.44 & -0.68 \\
Box 3 & -0.06 & -0.07 \\
Land & 0.13 & 0.12 \\
Sea & -0.16 & 0.04 \\
Box 4 Sea & 0.47 & 0.47 \\
Box 1/Box 2 & $-0,53$ & -0.68 \\
Land & -0.60 & -0.84 \\
Sea & -0.23 & -0.36 \\
\hline
\end{tabular}

Notes: The last three rows show the correlations between the precipitation in Boxes 1 and 2. Correlation coefficients greater than $r=0.49$ (annual) and $r=0.24$ (DJFM) are statistically significant at the 99\% confidence level of a $t$-test.

of oceanic precipitation is in the winter months December and January, while the minimum is in May-July. The largest amplitude of $3.5 \mathrm{~mm} \mathrm{~d}^{-1}$ is found in the storm track region of the central North Atlantic (Fig. 3e) with values ranging from $2.3 \mathrm{~mm} \mathrm{~d}^{-1}$ in the summer months up to $5.8 \mathrm{~mm} \mathrm{~d}^{-1}$ in January. For the other regions, the amplitude of oceanic precipitation ranges from 1.5 to $2.5 \mathrm{~mm} \mathrm{~d}^{-1}$. The eastern US (Fig. 3d) exhibits a secondary maximum in September which is coincident with the peak of the hurricane season. Also, the signal in Box 3 is comparably noisy due to high variability over the Gulf Stream.

As the annual cycle of overland precipitation differs in phase for the individual regions, the total signal for the North Atlantic regions is very weak with hardly discernible maxima in June/July and November/December (Fig. 3a). For two regions, northern Europe and the eastern US (Figs. 3b and d), the peak of overland precipitation is found in July and June, respectively and it is strongly out of phase with the oceanic precipitation. In Box 1, the lowest overland precipitation values are found in April and May. For Box 3 the minimum occurs in October and a secondary minimum is found in December. In the Mediterranean region (Box 2) oceanic and land precipitation are in phase (Fig. 3c) with the maximum occurring in December and the minimum in
July. The amplitudes of the annual cycle over land are smaller compared to the oceanic part in all subregions. The highest amplitude is found for Box 3 with approximately $1.5 \mathrm{~mm} \mathrm{~d}^{-1}$. For Boxes 1 and 2 the amplitudes are below $1 \mathrm{~mm} \mathrm{~d}^{-1}$.

\subsection{Temporal variability}

The anomaly time series for the entire North Atlantic region (Fig. 3a) shows little variation with time for the mean precipitation and the land part. Generally, a higher variability is found for the oceanic part compared to the land. Deviations of up to $0.5 \mathrm{~mm} \mathrm{~d}^{-1}$ are found for the ocean compared to $0.2 \mathrm{~mm} \mathrm{~d}^{-1}$ for the land. During the period of persisting high values of the NAO index in the early 1990s, a weak positive anomaly is found for the oceanic precipitation in the winter seasons 1991/1992 and 1992/1993. In the years 1988-1990, when periods of strong $\mathrm{NAO}+$, but also NAO- occurred, the precipitation is mostly below average. During the years with a prevailing negative NAO index, 1995-1997, the precipitation does not show a uniform response. The correlations from Table 1 suggest a weak anticorrelation of oceanic precipitation and the NAO index for the North Atlantic region while the precipitation over land is not correlated with the NAO index. This indicates rather a regional redistribution of precipitation depending on the state of the NAO than a variation of the total mean North Atlantic precipitation.

A more pronounced dependence of precipitation on the NAO is found for Boxes 1 and 2 (Figs. 3b and c). The northern European precipitation in Box 1 shows large variability for the oceanic and land precipitation. Distinct peaks in oceanic precipitation coincide with the winters 1991/1992 and 1992/1993 during the persistent $\mathrm{NAO}+$ phase with anomalies of 1 and $1.5 \mathrm{~mm} \mathrm{~d}^{-1}$, respectively. The overland precipitation exhibits a strong positive anomaly coinciding with $\mathrm{NAO}+$ conditions for January-March 1990 and by the end of 2006 and a minimum in the low NAO index winter season of 1995/1996. Both, land and ocean precipitation are positively correlated with the NAO index. During the winter months, the precipitation over land is highly correlated to the NAO index with $r=0.84$ (Table 1) while the correlation for precipitation over the ocean is weaker with $r=0.38$.

In the Mediterranean region (Box 2) an opposite response of precipitation to the NAO occurs compared to Box 1, albeit the anomalies are weaker and mostly of the same magnitude for land and ocean as shown in Fig. 3c. Distinct positive anomalies appear for the strong negative phase of 1995/1996 and from 2002 to 2006 when the NAO index was generally slightly negative. The precipitation in Box 2 and the NAO index are negatively correlated with values around $r=-0.7$ for the winter season. Moreover, the inverse response of precipitation in northern Europe and the Mediterranean is evident from Table 1 as the correlation of precipitation in Boxes 1 and 2 is negative with $r=-0.68$ for the winter months and $r=-0.53$ for the annual 
mean. Over land the anticorrelation is even higher with $r=$ -0.84 , while it is lower over the ocean with $r=-0.36$.

In contrast to the European sector, the precipitation in Box 3 (Fig. 3d), representative for the eastern US, exhibits a very noisy time series which does not correlate with the NAO index. Singular events such as the 1992/1993 El Niño, which was followed by a severe drought in the southeastern US (Lott, 1994), are clearly visible in the anomaly time series in Fig. 3d. Also the strong El Niño event of 1997/1998 causes a positive precipitation anomaly.

In the storm track regions of the central North Atlantic (Box 4, Fig. 3e) distinct peaks in the precipitation anomaly are mostly found during the wintertime. Annual mean and monthly wintertime precipitation are equally correlated with the NAO index for this Box with $r=0.47$. The anomaly time series in Fig. $3 \mathrm{e}$ reflects the long-term fluctuations of the NAO index with more positive values from the beginning of the record until the middle of the 1990s followed by mostly negative values until 1998. The peak positive anomaly in February 1997 concurs with the highest value of the NAO index for the investigated time series.

\section{Precipitation composites}

From the nineteen 4-month winter periods (December to March) of the years 1988-2007, composites for NAO+ and NAO- conditions have been constructed by selecting the months corresponding to the upper/lower quartile of the NAO index values. Thus these composite fields represent the mean precipitation for pronounced high/low NAO states and should reveal systematic regional differences between the NAO+ and NAO- states. Fig. 4 shows the resulting fields for the NAO+ (top left-hand panel) and the NAO- (top right-hand panel) phase as well as the difference map of both (bottom panel). Whether this sample difference between the NAO+ and NAO- composites is statistically significant has been tested with a non-parametric Mann-Whitney $U$-test (Mann and Whitney, 1947).

For the NAO+ composite shown in Fig. 4 (top left-hand panel) the pronounced storm track is clearly evident by a band of strong precipitation extending from the Gulf Stream along the North American east coast and over the central North Atlantic between Newfoundland and the British Isles. Maximum precipitation occurs in the cyclogenesis regions over the Gulf Stream offshore the North American east coast and in the Labrador outflow region with values of more than $10 \mathrm{~mm} \mathrm{~d}^{-1}$. Two other distinct maxima at the western coasts of Scotland and Norway result from the interaction of the enhanced storm track with orography. At the mountain ranges of the Scottish Highlands and the Norwegian coast, orographic rainfall is induced through the uplifting of air masses. In the leeward regions of the mountains significantly lower rain rates are found in the Baltic and North Sea as well as in the lee of Iceland. In the southeastern US, precipitation rates are up to $6 \mathrm{~mm} \mathrm{~d}^{-1}$, whereas most of southern
Europe, northern Africa, and the Mediterranean Sea suffer from very low precipitation of about $1 \mathrm{~mm} \mathrm{~d}^{-1}$ during $\mathrm{NAO}+$ phases.

For NAO- phases (Fig. 4, top right-hand panel), precipitation in the Mediterranean region exhibits distinctly higher values. In the western part of the Iberian peninsula and along the northern coasts of the Mediterranean precipitation rates of up to $6 \mathrm{~mm} \mathrm{~d}^{-1}$ are found in this situation. Local maxima appear due to orographic lifting at the east coast of the Adriatic Sea and at the Atlantic coast of the Iberian Peninsula. The northern European west coasts exhibit now smaller, but still relatively high rain rates up to $6 \mathrm{~mm} \mathrm{~d}^{-1}$. However, the precipitation maximum over the high latitude North Atlantic in the region between the southeastern coast of Greenland and the British Isles has vanished in the NAO- composite and rain rates of only $2-3 \mathrm{~mm} \mathrm{~d}^{-1}$ appear in this region. In the southeastern US, the precipitation still exhibits values up to $6 \mathrm{~mm} \mathrm{~d}^{-1}$, but the spatial extent of the local maximum is smaller for NAO- compared to the NAO+ phase. The band of strong precipitation over the Gulf Stream is slightly extended to the south compared to NAO+ conditions, but weaker in its centre. However, in the oceanic region between the Azores and western Europe a southward shift of the precipitation patterns is evident and the precipitation rates are increased to $4 \mathrm{~mm} \mathrm{~d}^{-1}$.

The difference map of the composites for NAO+ and NAO(Fig. 4, bottom panel) illustrates the systematic deviations in the precipitation pattern for the two NAO states. Positive values (red) correspond to more precipitation during $\mathrm{NAO}+$, negative values (blue) indicate higher precipitation during NAO- phases. The region, where the samples corresponding to the $\mathrm{NAO}+$ and NAO- composites differ significantly on the 99\% level from each other, is denoted by a black line in the difference map. The characteristic quadrupole pattern is resembled over land and in coastal regions by positive precipitation values in the southeastern US and northern Europe and negative precipitation values in northeastern Canada and the Mediterranean region, respectively. Except for the southeastern US, the difference NAO+ and NAO- patterns is mostly significant in these regions. Over the ocean, distinct anomalies are found over the Gulf Stream and in the storm track regions of the North Atlantic. In the western North Atlantic Gulf Stream region the patterns are mostly not significant due to the high statistical variability. However, the meridional shift of the storm track depending on the NAO phase is evident by the significant dipole precipitation pattern over the central and eastern North Atlantic. Associated with this shift is a change in the moist air masses, which are conveyed by the Westerlies to the coastal regions of Europe that are directly exposed to the storm track, where they lead to enhanced precipitation depending on the state of the NAO. Hence, the strongest positive signals are found at the Scottish and Norwegian coast for NAO+ and the strongest negative signal is located at the Iberian peninsula for NAO-. Over the ocean, the positive signal over the North Atlantic is more pronounced than the negative anomaly, indicating a stronger response of the storm track during 


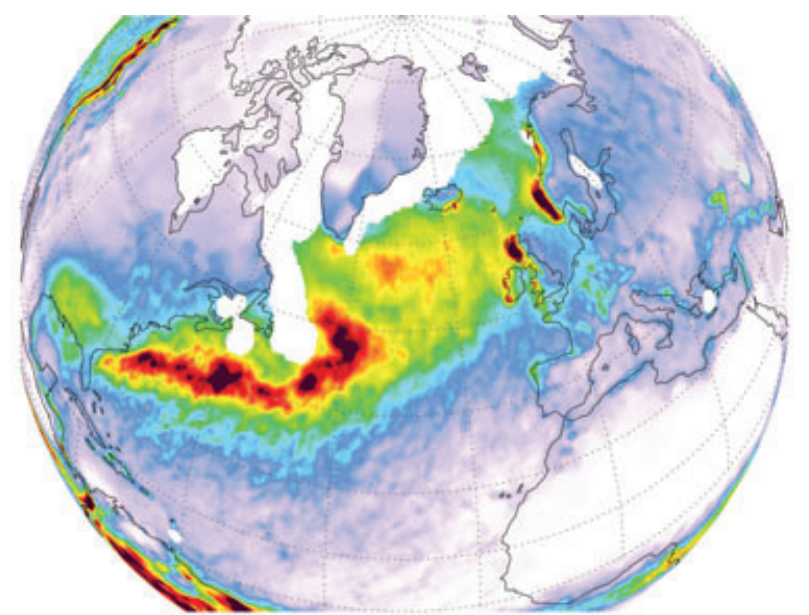

HOAPS-3_GPCC RAIN NAO+ (upper quartile) [mm/d]

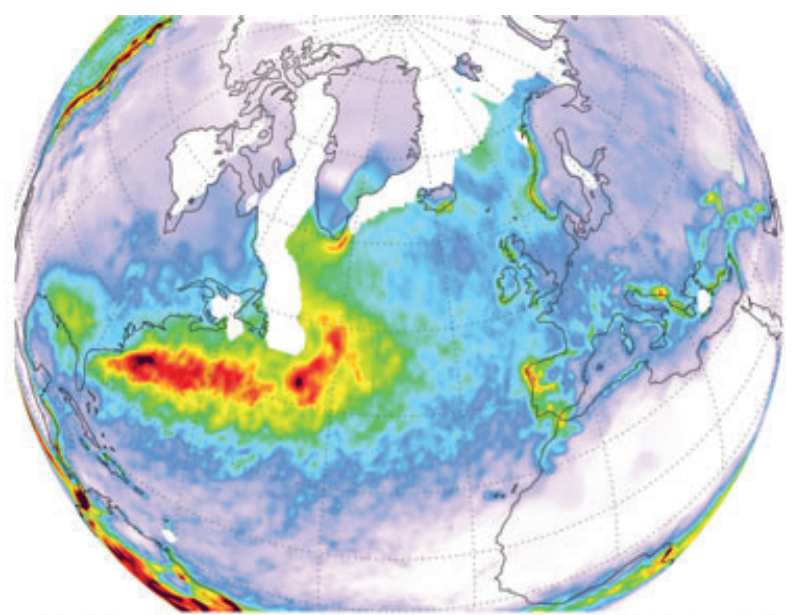

HOAPS-3_GPCC RAIN NAO- (lower quartile) [mm/d]

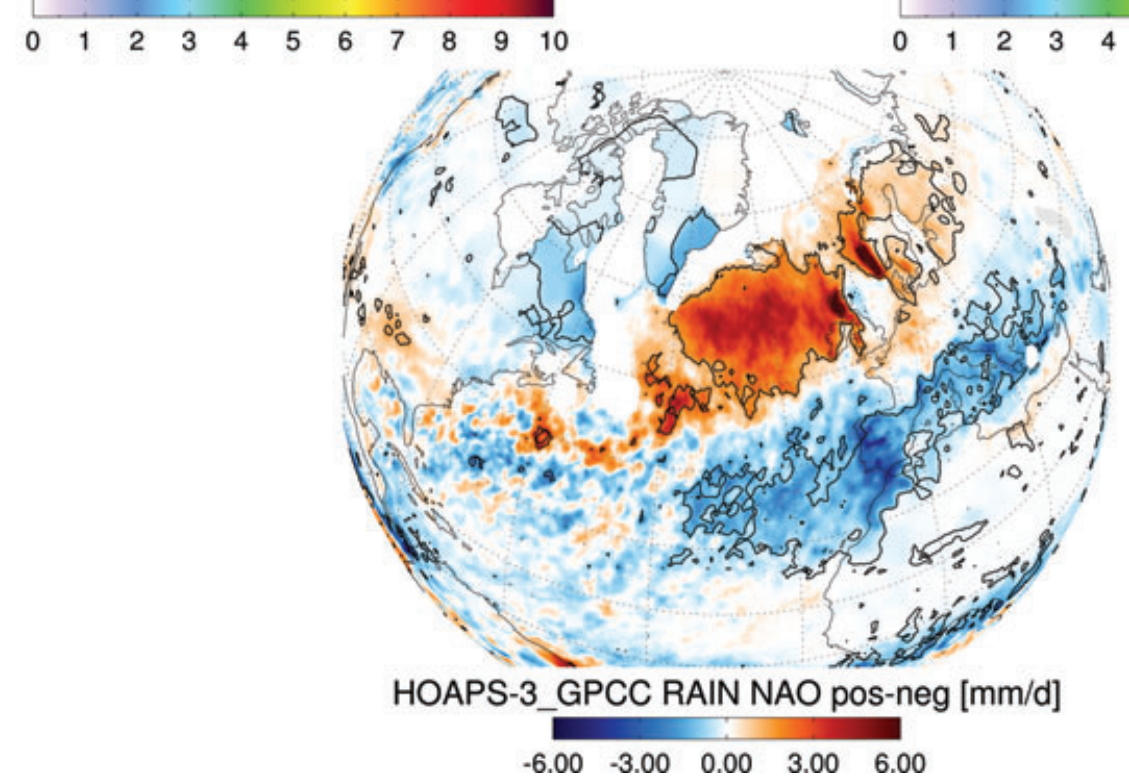

Fig. 4. Composite fields of precipitation from the corresponding time steps for the upper quartile of NAO index values (top left-hand panel), the lower quartile of NAO index values (top right-hand panel) and the difference of both composites. The black line in the difference plot indicates where both samples differ on the $99 \%$ significance level of a Mann-Whitney $U$-test.

$\mathrm{NAO}+$ phases. The high resolution of the data set additionally reveals some small scale features such as the negative response of precipitation and the NAO index over the North Sea and the Baltic Sea, which are caused by mountain lee effects (Uvo, 2003).

\section{Global precipitation correlation patterns}

To elaborate on the influence of the NAO on global precipitation beyond the North Atlantic region, global correlation maps of the precipitation with the monthly NAO index for the December to March winter season are shown in Fig. 5. Apart from the correlations of the NAO index and the HOAPS-3/GPCC data set, the correlation patterns of several data products are depicted for comparison. Additionally, the correlation of HOAPS-3/GPCC with an alternative NAO index from $\mathrm{CPC}$, the $\mathrm{AO}$ index, and the ENSO related Southern Oscillation (SO) index are shown in Figs $5 b, g$ and $h$.

All correlations were calculated using the non-parametric Spearman's rank correlation method. The significance of the resulting correlation patterns is determined with a two sided $t$-test (Wilks, 2006). The precipitation data was locally deseasonalized and detrended prior to the calculation of the correlations. Correlations that are not significant above the $95 \%$ level have been masked out. Thus only robust correlation patterns are shown. Regions south of $60^{\circ} \mathrm{S}$ are omitted since there is no data over land for this region and the ocean is mostly covered by sea ice. Correlations over the ocean could also not be 
(a)

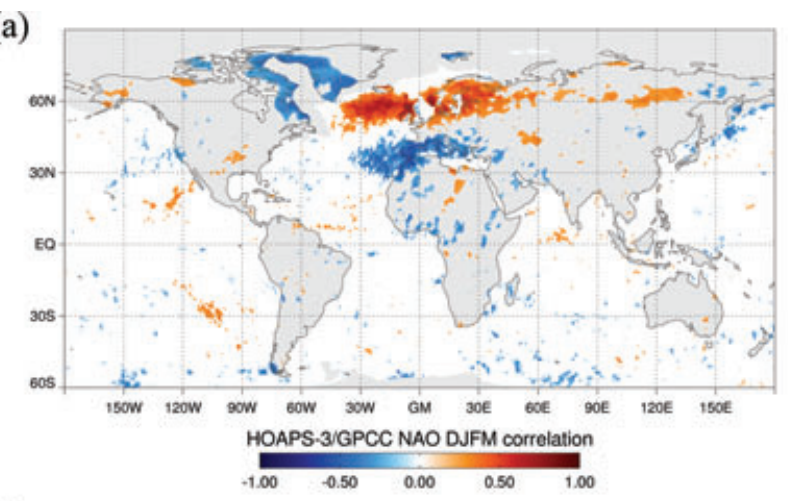

(c)

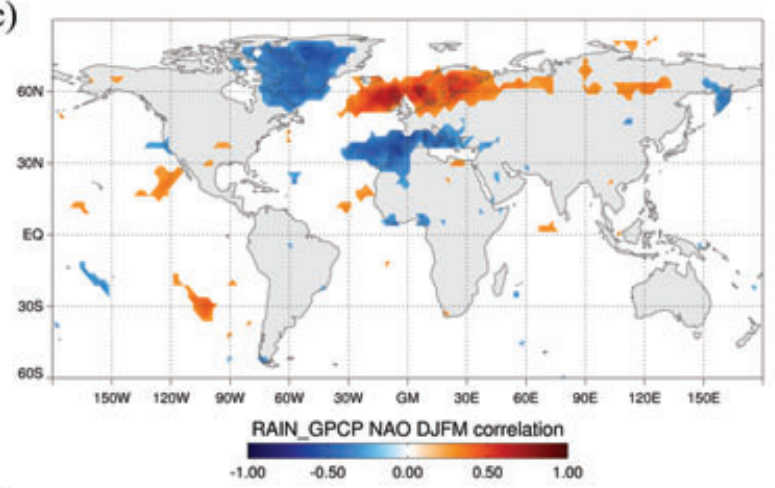

(e)

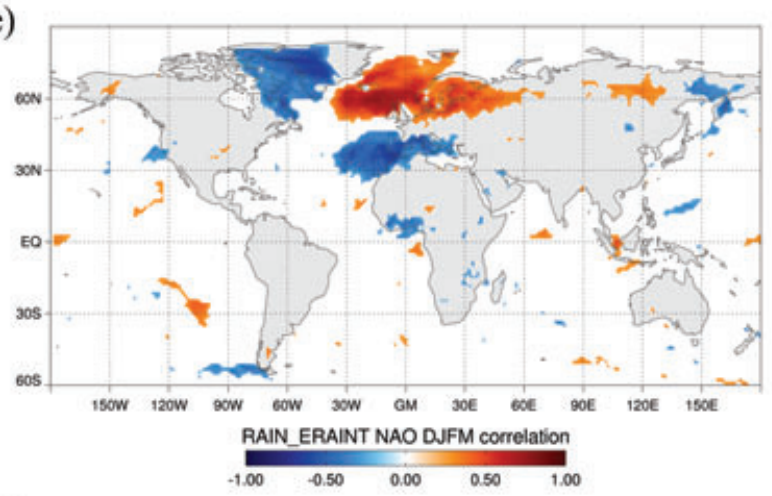

(g)

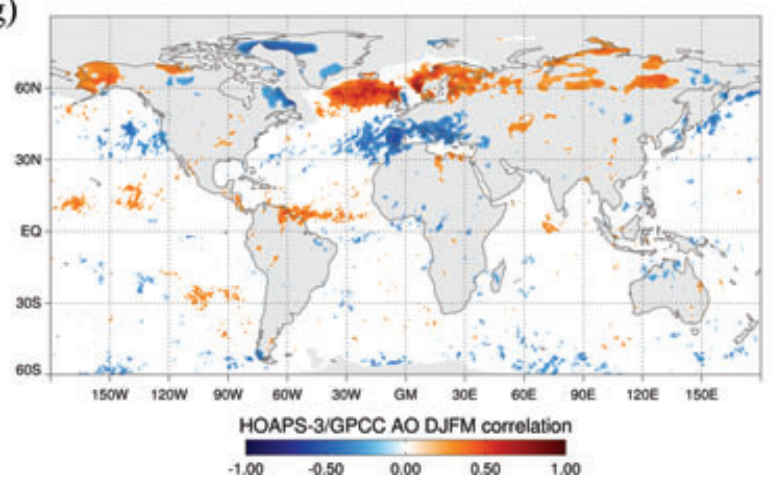

(b)

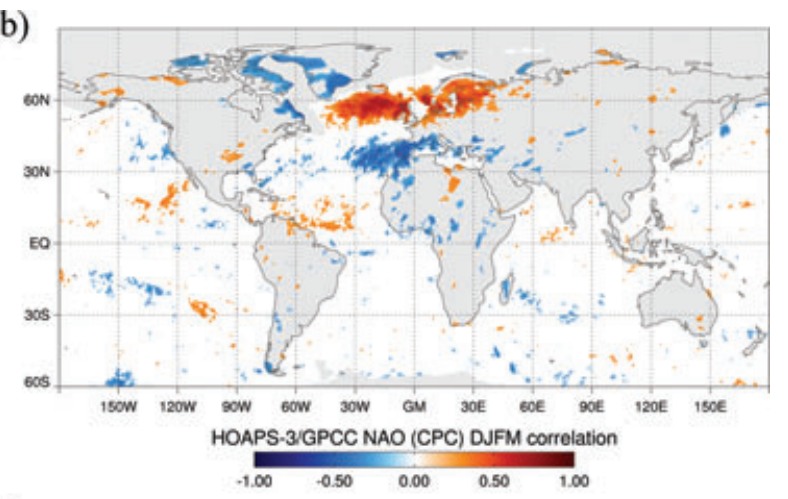

(d)

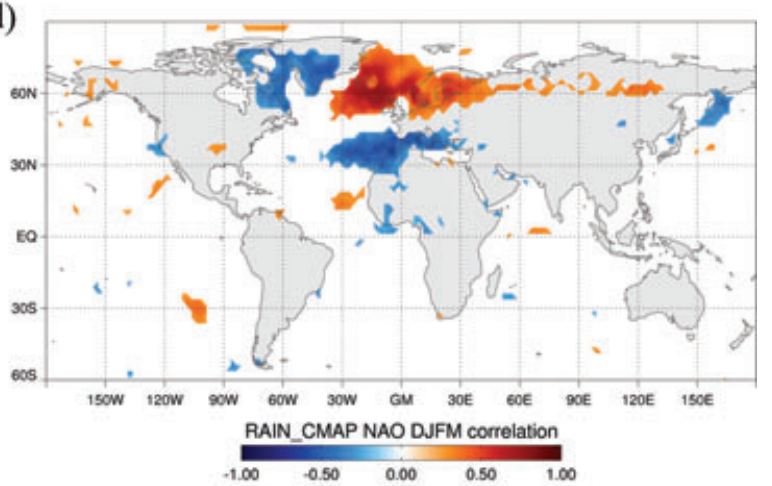

(f)

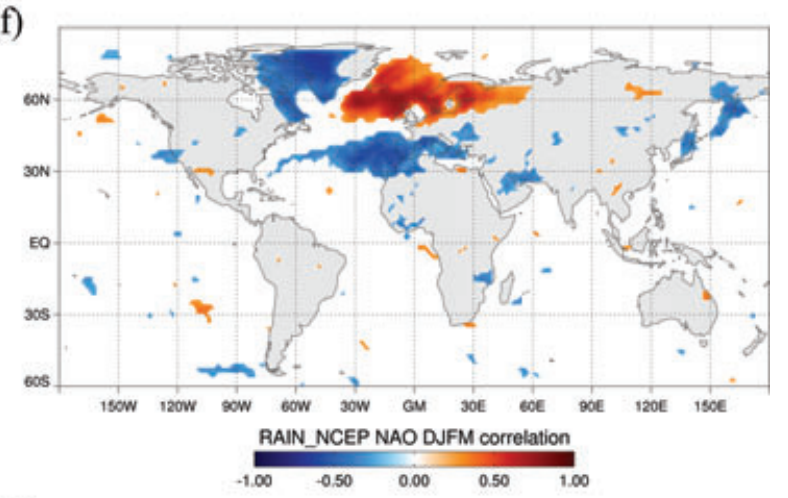

(h)

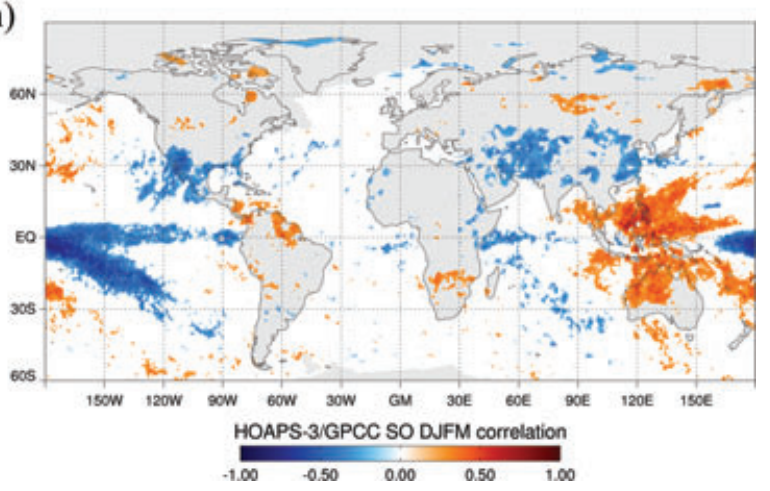

Fig. 5. Correlation patterns of monthly mean December to March precipitation from HOAPS-3 (a, b, g, h), GPCP V2 (c), CMAP (d), ERA interim (e), and NCEP-R2 (f) with the station based NAO index (a, c-f), CPC NAO index (b), AO index (g) and SO index (h). Only data with correlations above the 95\% significance level are shown. The time period is 1988-2005 (1989-2005 for ERA interim). Grey shaded ocean regions indicate domains excluded in HOAPS-3 due to the presence of sea ice (a, b, g, h). 
calculated for HOAPS-3/GPCC over the Baffin Bay and Labrador Sea region and over most of the Arctic Ocean due to the lack of retrieval in HOAPS-3 over sea-ice covered regions and are shaded grey.

The additional data sets are the satellite based GPCP V2 (Adler et al., 2003) and CMAP enhanced (version 809) (Xie and Arkin, 1997) products and the NCEP-R2 (Kanamitsu et al., 2002) and ERA interim (Simmons et al., 2007) reanalysis data sets. The CMAP enhanced product is not purely satellite based, as it is complemented with reanalysis data in data void regions. Also, GPCP and CMAP are not completely independent from GPCC over the continents as they use rain gauge data to constrain their retrievals over land. While the HOAPS-3/GPCC product has a grid of $0.5^{\circ}$, the resolution for the other data sets is $1.5^{\circ}$ (ERA interim) and $2.5^{\circ}$ (GPCP, CMAP, and NCEP-R2), respectively. The resolution of the HOAPS-3/GPCC data is considerably higher compared to the other data sets. Hence, some finer structures present in HOAPS-3/GPCC may not be resolved by the other products.

The CPC NAO index is calculated from the leading mode of monthly mean standardized $500 \mathrm{hPa}$ height anomalies using a RPCA technique (cf. http://www.cpc.noaa.gov/products/ monitoring_and_data/oadata.shtml), the AO index is constructed by projecting monthly mean $1000 \mathrm{hPa}$ height anomalies onto the leading EOF mode (cf. http://www.cpc.ncep.noaa.gov/ products/precip/CWlink/daily_ao_index/ao.shtml), and the SO index is based on the Standardized Tahiti - Darwin pressure difference (cf. Trenberth, 1984, http://www.cgd.ucar.edu/cas/ catalog/climind/soi.html).

For the North Atlantic region, all correlation patterns in Fig. 5 agree well with the difference map of the $\mathrm{NAO}+/-$ composites (Fig. 4). Several well-connected regions of significant correlations can be identified in the Labrador Sea region, the eastern Atlantic, and over Europe. In the western Atlantic and over the eastern continental US the correlations are mostly weak and not significant. A large pattern of significant positive correlation, that is, precipitation increase during $\mathrm{NAO}+$ phases, extends from the northeast Atlantic across northern Europe to Siberia. The highest correlations occur at the northwestern European coasts and in the storm track between Newfoundland and the British Isles. Significant negative correlations with the NAO index are located in the region extending from the Azores across the Mediterranean into the Middle East, and in the land area adjacent to the Baffin Bay and Labrador Sea.

The characteristic pattern of significant correlations is basically resolved in all data sets and is also evident for the CPC NAO index (Fig. 5b). However, some differences remain for the North Atlantic and for global teleconnections.

In the subpolar regions, substantial differences occur in the Nordic Seas and the Labrador Sea. HOAPS-3/GPCC data is not available in some parts of these regions due to the disturbing presence of sea ice. The reanalysis products and CMAP exhibit a strong positive correlation with the NAO index over the Nordic
Seas north of $60^{\circ} \mathrm{N}$, which is not present in the GPCP data. Also, the extent of the significant pattern over the Labrador Sea and western Greenland varies between the data sets. The patterns over northeastern Canada agree quite well, including HOAPS-3/ GPCC, while the patterns for Greenland differ. The reason for the inconsistencies at high latitudes are due to deficiencies of satellite retrievals, that often lack skill to detect frozen precipitation properly and the generally poor data coverage of other input data for the reanalyses (Adler et al., 2001). HOAPS-3 seems to have a high potential for improving this situation as is shown in a companion paper in this special issue by Klepp et al. (2010).

At North Atlantic mid-latitudes, the negative correlation pattern extending from the central North Atlantic eastward over the Mediterranean region is represented in all data sets. In the NCEP-R2 (Fig. 5f) data, a narrow band of significant negative correlation extends this pattern to the Gulf Stream region in the western Atlantic. A similar but much weaker pattern which is related to the southward broadening of the precipitation over the Gulf Stream patterns during NAO- phases is evident over the western Atlantic in the correlation of HOAPS-3/GPCC and the CPC NAO index (Fig. 5b).

At the northeastern African Mediterranean coast, precipitation is positively correlated with the NAO index in all data sets. This pattern extends to central northern Africa in HOAPS-3/ GPCC. As this is not the case for the compared data sets, this is likely due to sparse data sampling of the GPCC product (see Section 3).

Some differences between the data sets appear in the Middle East and the Arabian peninsula. Except for ERA interim, all data sets exhibit at least a small patch of negative correlation at the Turkish/Syrian border adjacent to the eastern tip of the Mediterranean Sea. NCEP-R2 is moreover significantly correlated with the NAO index in the Persian Gulf region, while this feature is much weaker in the other data sets.

For the equatorial Indian Ocean, a small patch of positive correlation of precipitation with the NAO index is found southwest of the tip of the Indian subcontinent for all data sets, but NCEP-R2. Positive NAO phases are known to be correlated with warm SST anomalies in the Indian Ocean (Hoerling et al., 2001; Bader and Latif, 2005). These SST anomalies are associated with enhanced tropical convection and hence more precipitation. Such a relationship of significantly increased monthly convection in the Indian Ocean and positive NAO phases has also been shown by Miller et al. (2003) using outgoing long-wave radiation (OLR) from NCEP reanalysis and satellite observations of the NASA Earth Radiation Budget Experiment (ERBE).

Another tropical feature is evident in all data sets over western central Africa, where the precipitation is negatively correlated with the NAO index. Several studies suggest a feedback of tropical SST variations and the NAO (e.g. Marshall et al., 2001; Hurrell et al., 2003, and references therein). The tropical circulation is influenced by the modulation of the trade 
winds through the NAO. On the other hand, the position and strength of the Intertropical Convergence Zone (ITCZ), as well as the extratropical circulation show a response to the cross equatorial meridional SST gradient. Hence the precipitation and surface fluxes in the tropical Atlantic and adjacent continental regions are modulated by this tropical NAO feedback. A coherent response of oceanic wind speed and evaporation along the tropical west African coast is evident from HOAPS-3 data (not shown).

The statistical response of tropical Atlantic precipitation to the NAO turns out to be sensitive to the NAO index chosen as a reference. When the principal component based CPC NAO index is used (Fig. 5b), a positive correlation pattern in the western tropical Atlantic emerges. This pattern is present for the correlation with the AO index (Fig. 5g) as well. A similar feature was found by Mariotti and Arkin (2007).

More NAO related teleconnections are indicated by correlation patterns in the Pacific. Over the eastern Pacific and North America a dipole structure extending from the subtropics to the mid-latitudes is evident in HOAPS-3/GPCC and, to some extent, in the other data sets as well. This pattern may be associated with a teleconnection of the NAO to variability in the Pacific. Furthermore, positive correlations of precipitation and the NAO index are found in Alaska at the position of the Aleutian low. An even stronger link of North Atlantic to Pacific patterns is found for the correlation with the AO index, which is strongly correlated with the NAO in wintertime. As shown in Fig. $5 \mathrm{~g}$, the patterns in the Pacific region and over Siberia are stronger while the Atlantic correlations are similar to those for the NAO index. A direct link of atmospheric variability in the North Atlantic and Pacific is still debated. Ambaum et al. (2001) suggests a weak anticorrelated relationship between the average zonal flow in the Atlantic and Pacific which is also indicated by the inverted structure compared to the NAO pattern in the North Atlantic. Furthermore, Wallace and Thompson (2002) argue that the Pacific North American (PNA) pattern could also be represented by a second mode of $500 \mathrm{hPa}$ height EOFs which is out of phase with the AO.

In the southeastern Pacific, all data sets exhibit a patch of positive correlation, which may be related to ENSO. The ENSO is the most prominent atmospheric oscillation pattern on the globe, accounting by far for most of the variability in the Pacific, and has significant impact on distant regions. Fig. 5h shows the correlation of HOAPS-3/GPCC precipitation with the SO index. Negative values of the SO index are associated with El Niño events and positive values indicate a La Niña phase. Except for the characteristic precipitation anomalies in the tropical Pacific, distinct effects on the precipitation are evident throughout Asia and Africa. In the Atlantic sector, especially for the southern US and central America significant correlations are also found. This is in accordance with results from Huang et al. (1998) who showed that large-scale atmospheric circulations such as the PNA and the NAO are influenced by the ENSO and found significant modes of coherent variability between ENSO and the NAO for about $70 \%$ of warm ENSO events.

\section{North Atlantic Freshwater Budget}

While the main focus of this paper lies on the analysis of precipitation, another important factor is the heat and moisture exchange of the atmosphere with the underlying ocean.

The freshwater input into the ocean affects the surface salinity and hence the density and stratification of the upper ocean layers. Consequently, surface freshwater variations have the potential to influence the ocean circulation. Dickson et al. (2000) showed that the NAO has a significant impact on the ice and freshwater export from the Arctic. Walsh and Portis (1999) and Bojariu and Reverdin (2002) investigated the freshwater balance of oceanic evaporation and precipitation for the North Atlantic using NCEP and ERA reanalysis data. For longer periods of NAO anomalies are found to have a significant effect on the surface salinity by changes in the regional freshwater flux. Although this link could be established, it is not certain that the effect is strong enough to influence deepwater formation and the strength of the thermohaline circulation (THC, Hurrell, 1995a; Greatbatch, 2000).

HOAPS-3 latent and sensible heat fluxes are estimated using a bulk approach which depends on the wind speed, the near surface humidity difference, and air temperature differences as input parameters (see Section 3). Hence, the ocean freshwater flux, that is, the difference of evaporation and precipitation (E-P), is available from HOAPS-3. Figure 6 shows the local correlation of the deseasonalized and detrended HOAPS-3 fields of freshwater flux and related bulk parameters with the NAO index for the winter months December to March.

The correlation of the wind speed (Fig. 6b) with the NAO index reflects the direct response of the wind field to the strengthened meridional pressure gradient in the $\mathrm{NAO}+$ phase. The positive correlation patterns are associated with the northward shift and strengthening of the Westerlies and enhanced trade winds in the tropical regions, while the negative correlations indicate the stronger winds at mid-latitudes during NAO- phases.

During NAO+ phases, the strengthened winds north of $50^{\circ} \mathrm{N}$ in the central Atlantic are related with advection of cold, dry Arctic air masses into the southwest sector of the Icelandic low, which leads to an increase in the humidity difference (Fig. 6c). Together with the enhanced wind speed, this results in a positive response of evaporation and sensible heat flux in this region, which in turn leads to a cooling of the underlying ocean surface. An opposite effect can be observed in the southeastern sector of the Icelandic low around the British Isles and the North Sea, where warm, moist air is advected in NAO+ conditions, causing a decrease in the humidity difference. Hence the heat fluxes are reduced and negatively correlated with the NAO index, although the SST of the North Sea is positively correlated. During NAOphases the response of the North Sea region is negative as the 
(a)

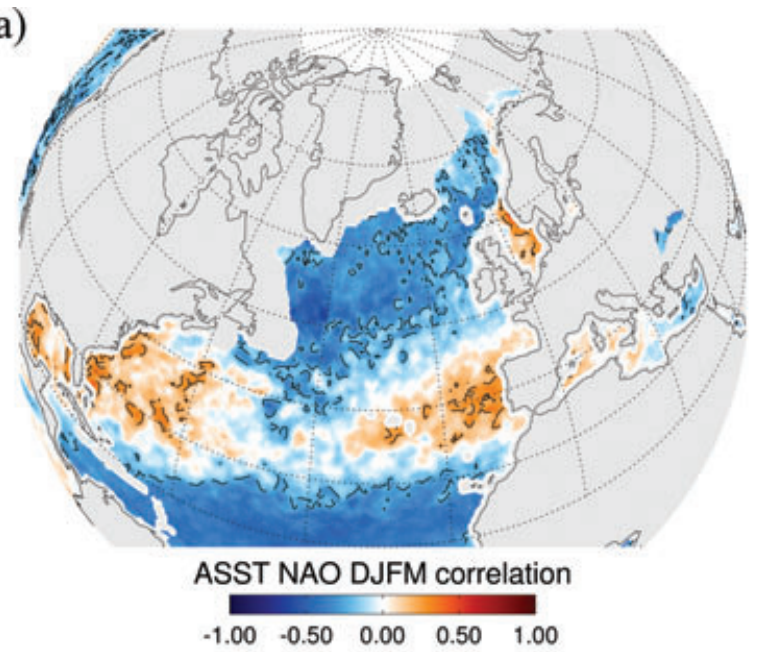

(c)

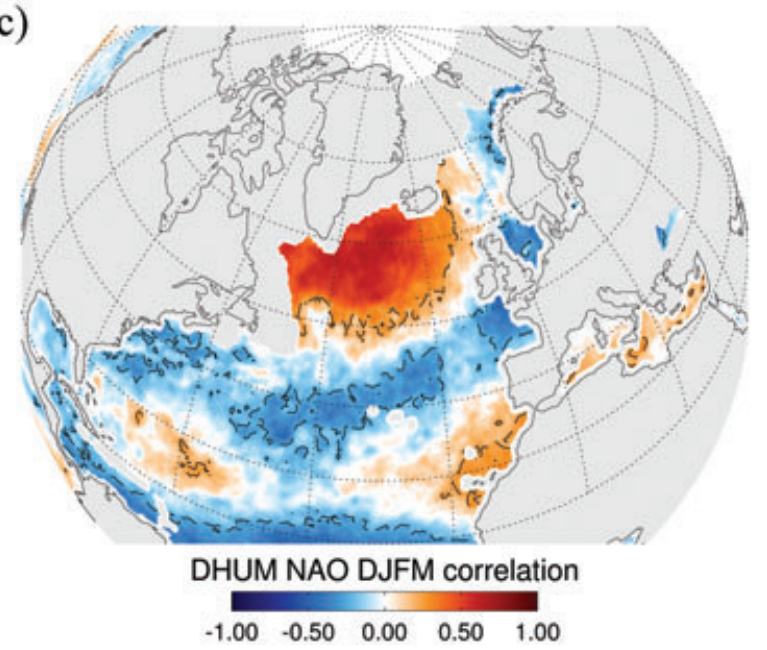

(e)

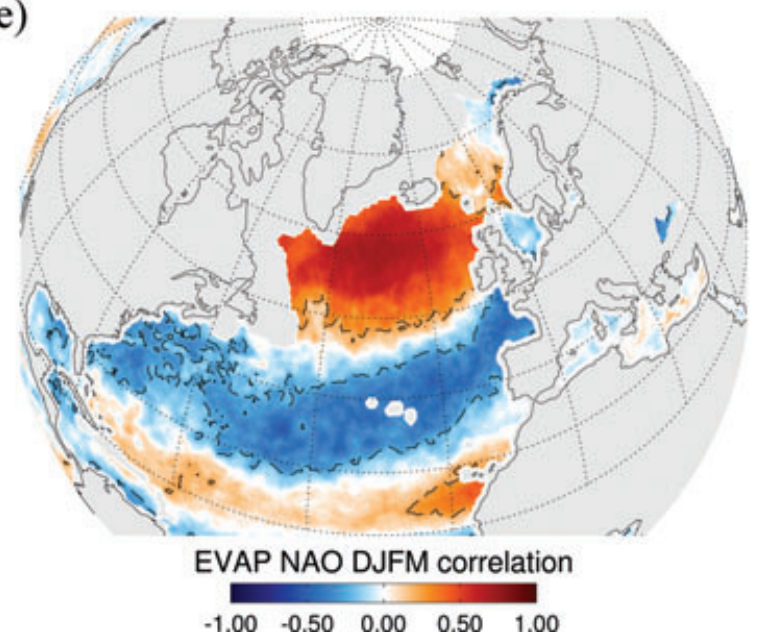

(b)

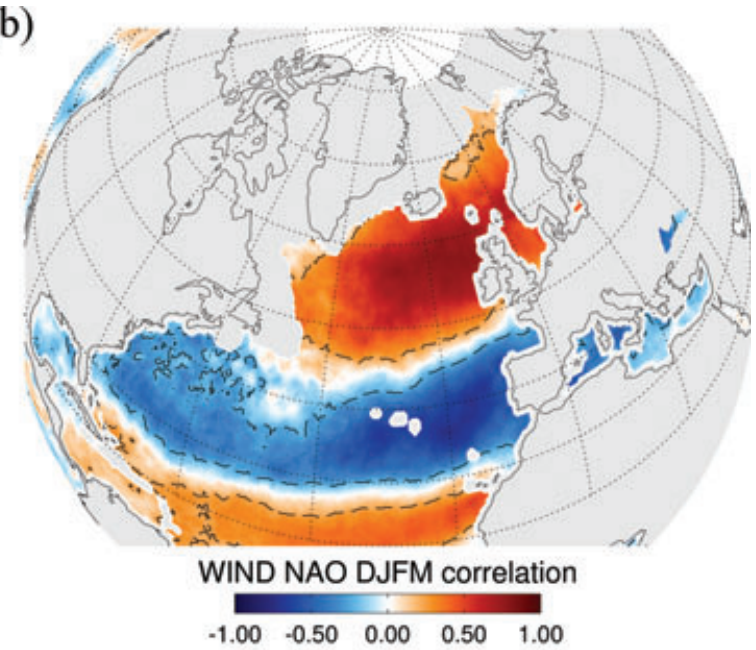

(d)

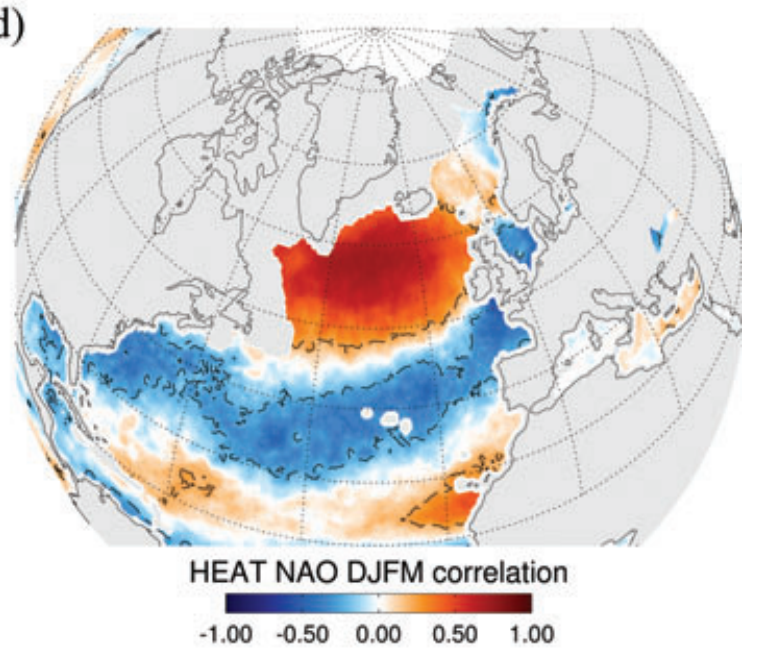

(f)

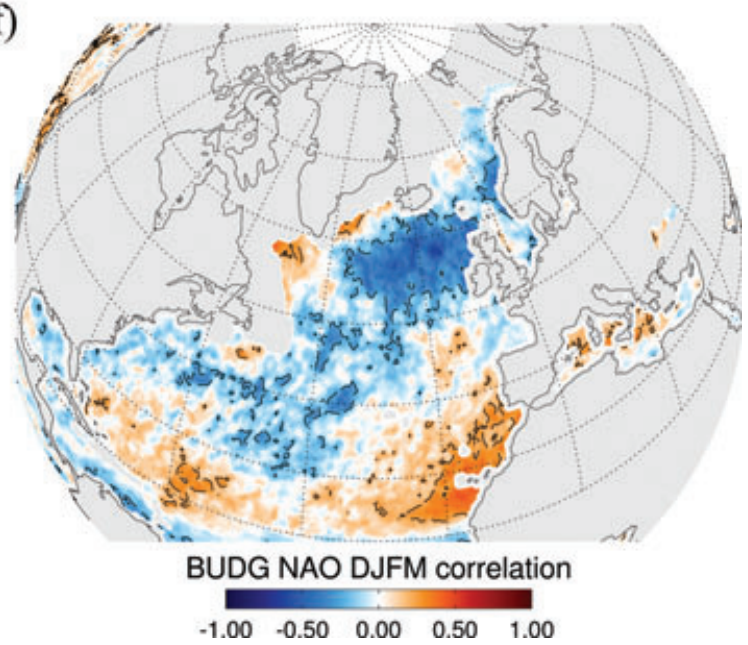

Fig. 6. Local correlations of HOAPS-3 freshwater flux related parameters with the NAO index for the months December to March. The parameters depicted on the panels are (a) SST, (b) wind speed, (c) difference in humidity, (d) sensible heat flux, (e) evaporation and (d) freshwater flux. The dashed line indicates the $95 \%$ significance level of the $t$-test. Grey shaded ocean regions indicate domains excluded in HOAPS- 3 due to the presence of sea ice. 
advection of cold and dry air masses from the Arctic leads to enhanced heat exchange and cooling of the sea surface.

The feedback of the sensible heat flux and the evaporation (Figs. 6d and e) on the wind is most pronounced at the mid to high latitudes over the North Atlantic, where both are significantly correlated with the NAO index. At high latitudes the humidity difference appears as a strong driver for the surface flux response as it is highly correlated with the NAO index. At the mid-latitudes and subtropics the correlations are lower because the horizontal humidity gradients over the ocean decrease towards the tropical regions, and advection of air masses has a less pronounced effect on the near surface humidity difference. In the central North Atlantic the humidity difference is significantly correlated with the NAO index, but in the subtropics the response of the heat fluxes is mainly triggered by the modulation of the wind speed through the NAO as correlations for humidity difference are rather low and mostly not significant. However, in the region around the Canary islands, where dry continental air masses from the Sahara are advected over the ocean within the trades, a significant positive correlation of the humidity difference and heat fluxes is evident. A similar effect is evident at the North American east coast, where more cold air outbreaks reach the Gulf Stream region during NAO- conditions.

The correlations of the SST (Fig. 6a) with the NAO index exhibit a well-known largely significantly correlated tripole structure (e.g. Cayan, 1992a; Visbeck et al., 1998) with negative values in the subpolar and the subtropical North Atlantic and mostly positive correlations at the mid-latitudes. This pattern appears inverted to the correlation patterns of wind speed and the evaporation and sensible heat fluxes, which suggests a direct response of the SST field to the fluxes depending on the state of the NAO. The wind driven surface fluxes cause a cooling of the sea surface, imprinting the signature on the SST. Moreover, the wind induced mechanical mixing contributes to the cooling upper-ocean temperature field, albeit the effect it less pronounced compared to the heat exchange by sensible heat and evaporation (Cayan, 1992a). The heat extraction from the ocean is of great importance for the moderate climate in northwestern Europe. When the NAO index is high, the stronger westerly winds lead to an amplification of the heat release from the North Atlantic into the atmosphere, which is then advected over the continent. Apart from the direct effects of the atmosphere on the SST, long term SST variations on decadal timescales have been identified that may be part of a dynamically coupled ocean-atmosphere feedback affecting the NAO variability (Deser and Blackmon, 1993; Visbeck et al., 1998; Czaja and Marshall, 2001). On shorter timescales, SST anomalies preceding NAO phases by some months might imply some forecast potential for the NAO (Czaja and Frankignoul, 1999; Hurrell et al., 2003).

The correlation for the freshwater flux from HOAPS-3 with the NAO index is shown in Fig. 6f. Since both components, the precipitation (Fig. 5a) as well as the evaporation (Fig. 6e) exhibit distinct significant correlation patterns with the NAO index, these are reflected in the correlation of the freshwater flux with the NAO index.

In the northeast Atlantic at latitudes north of $50^{\circ}$, the correlation of E-P with the NAO index is negative. Here both parameters, the precipitation and evaporation are positively correlated with the NAO index. The resulting negative correlation of E-P with the NAO index, implies that the positive precipitation anomalies exceed the increase in evaporation during NAO+ phases. Hence the precipitation dominates the variability of the freshwater flux in this region.

For the mid-latitudes, the E-P correlations in the Gulf Stream region, the eastern Atlantic and the Mediterranean are mostly inverse to the precipitation patterns indicating a stronger influence of the precipitation on the freshwater flux compared to the evaporation, similar to the high latitudes. However, the correlations of the freshwater flux with the NAO are often not significant. In the central mid-latitude Atlantic and the subtropics, the evaporation signal mostly determines the correlations patterns. A region of significant positive E-P correlation with the NAO index is found extending from the Iberian Peninsula across the Canary islands to the southwest. Here, the opposite correlations of precipitation and evaporation result in an amplification of the freshwater flux into the atmosphere during $\mathrm{NAO}+$ phases.

\section{Discussion and conclusions}

The precipitation retrieved from a novel combined precipitation data set consisting of observational based data from the HOAPS-3 satellite derived product and the rain gauge based GPCC Full Data Reanalysis Product Version 4 has been assessed with respect to its response to the NAO during the December to March winter season. Additionally, the dependence of oceanic freshwater flux parameters on the NAO was investigated in a new analysis using HOAPS-3 satellite data. Compared to previous studies, the high resolution of the data sets allowed a more detailed identification of the structural changes in precipitation patterns and freshwater flux parameters that are induced by the atmospheric fluctuations associated with the NAO. Local features such as lee effects in the North Sea and Baltic Sea were found that are coherent with the regional and large-scale patterns.

Common to the entire North Atlantic and all subregions, a more pronounced annual cycle of the over-ocean precipitation compared to the overland values is evident from the HOAPS-3/ GPCC data set. A distinct dependence of precipitation on the NAO is found for the stormtrack region in the North Atlantic, northern Europe and the Mediterranean. A strong anticorrelation of the precipitation over northern and southern Europe is linked to the NAO. For the mean precipitation of the entire North Atlantic no dependence on the NAO index is found, suggesting rather a regional redistribution of precipitation depending on the state of the NAO than a variation of the total mean North Atlantic precipitation. 
Composites and correlation patterns of the precipitation agree well and show a remarkably detailed and homogeneous response to the NAO related variability with a convincing pattern consistency between the HOAPS-3 and the GPCC data sets. A significant impact of the NAO on the corresponding precipitation patterns is evident. The strongest influence occurs in the northeastern Atlantic and Europe as well as in the regions adjacent to the Baffin Bay and Labrador Sea.

The close connection of the meridional shift in precipitation and of the North Atlantic storm track with the NAO phase is evident from significant patterns in the composite and correlation analyses and confirms findings from previous studies (e.g. Carleton, 1988; Hurrell and van Loon, 1997; Rogers, 1997; Dickson et al., 2000; Mariotti and Arkin, 2007). For NAO+ conditions, a strong storm track extends from Newfoundland eastwards to Iceland and the British Isles and a local maximum southeast of Greenland is evident. For the NAO- phase, the storm track appears much weaker and shifted southward. As indicated by the precipitation composite patterns in Fig. 4, the response of a precipitation increase to $\mathrm{NAO}+$ is stronger than to NAO-. The displacement of the precipitation centres over the North Atlantic depending on the NAO index is in conformity with composites of synoptic activity based on cyclone tracking algorithms (e.g. Serreze et al., 1997; Sickmöller et al., 2000) or $500 \mathrm{hPa}$ geopotential height fields as shown by Trigo et al. (2002). These studies also indicate a decrease in the absolute number of cyclone activity for the NAO- phase and a southward shift of the storm track. During NAO+ phases, an increase in the number of storm systems along the storm track together with a slightly higher intensity as compared to the climatological mean is identified as the dominant signal.

On global scale, the influence of the NAO on global precipitation is evident by teleconnections patterns in global correlation maps. Especially for the Pacific, significant correlations of the precipitation with the NAO index are found. In the correlation patterns of the precipitation and the Northern Hemisphere mode of the AO index, this relationship is even more pronounced. The comparison of global correlation patterns of the NAO index and precipitation with other data sets shows an overall good agreement for the large-scale patterns, but regional differences remain, especially at high latitudes.

With a record of nineteen winter seasons and thus 76 months of data, an EOF analysis of the North Atlantic HOAPS-3/GPCC precipitation data set could be carried out. No details of that analysis are given in this paper but can be found in Andersson (2009). The major findings are summarized in the following. Due to the strong inherent small-scale intramonthly variability, the explained variance of the leading EOF is only around $10 \%$. Hence, no clearly dominating EOF pattern can be identified. Moreover, the first EOF rather reveals similarities with the East Atlantic Pattern defined by Barnston and Livezey (1987), while the second EOF clearly represents the variability associated with the NAO. Singular events such as a strong NAO+ or NAO- have a significant impact on the EOF patterns as well as strong El Niño events, such as in the winter 1997/1998. Apart from their limited expressiveness regarding the explained variance, the EOFs reveal coherent response and no land-sea difference or effect of changing station density was detected. This supports strongly our conviction of a successfully coherent merging of the two precipitation data sets over land and ocean.

In addition to previous studies, which are based on reanalysis data and ship observations (e.g. Hurrell, 1995a; Walsh and Portis, 1999; Bojariu and Reverdin, 2002; Hurrell et al., 2003), the HOAPS-3 data sets allows a new climatological analysis of the response of the freshwater flux to the NAO based on satellite data. From the analysis of HOAPS-3 freshwater flux parameters feedbacks of the evaporation and sensible heat to the wind speed and humidity difference could be identified. It also appears that the response to the NAO at mid and high latitudes is governed by the precipitation, and in the subtropical regions the feedback is mainly determined by evaporation. For the northern and mid-latitude Atlantic the correlation patterns shown in Fig. 6 agree qualitatively with previous findings. However due to large uncertainties in the tropical freshwater balance of the reanalysis products larger discrepancies between different data sets for these regions occur (Walsh and Portis, 1999). Hurrell (1995a) found only a weak correlation of E-P and the NAO index in the northeastern subtropical Atlantic by using ECMWF data to infer the vertically integrated moisture transport. This was not consistent with station-based data from this region. This disagreement is not evident in the HOAPS-3 freshwater flux, where a significant positive response to the NAO is clearly proven and in conformity with the station data. In particular, for the tropical regions HOAPS- 3 has the potential to improve the understanding of the related processes compared to reanalysis data.

\section{Acknowledgments}

This research was funded by the German Science Foundation (DFG) under grant SFB 512 'Cyclones and the North Atlantic climate system' and by the Helmholtz foundation through the Virtual Institut project 'Investigation of extratropical cyclones using passive and active microwave radars'. GPCC data was gratefully obtained from the website http://gpcc.dwd.de.

\section{References}

Adler, R. F., Huffman, G. J., Bolvin, D. T., Curtis, S. and Nelkin, E. J. 2000. Tropical rainfall distributions determined using TRMM combined with other satellite and rain gauge information. J. Appl. Meteor. 39(12), 2007-2023.

Adler, R. F., Huffman, G. J., Chang, A., Ferraro, R., Xie, P. and coauthors. 2003. The version-2 Global Precipitation Climatology Project (GPCP) monthly precipitation analysis (1979-present). J. Hydrometeor. 4(6), 1147-1167.

Adler, R., Kidd, C., Petty, G., Morissey, M. and Goodman, H. 2001. Intercomparison of global precipitation products: the third 
Precipitation Intercomparison Project (PIP-3). Bull. Amer. Meteor. Soc. 82(7), 1377-1396.

Ambaum, M. H. P., Hoskins, B. J. and Stephenson, D. B. 2001. Arctic Oscillation or North Atlantic Oscillation? J. Climate 14, 3495-3507.

Andersson, A. 2009. The HOAPS Climatology: Evaluation and Applications. PhD thesis, Berichte zur Erdsystemforschung 72, Universtät Hamburg, Max-Planck-Institut für Meteorologie, Hamburg, Germany. ISSN 1614-1199.

Andersson, A., Bakan, S., Fennig, K., Graß1, H., Klepp, C. and co-authors. 2007. Hamburg Ocean Atmosphere Parameters and Fluxes from Satellite Data-HOAPS-3-monthly mean. World Data Center for Climate. electronic publication, doi:10.1594/WDCC/HOAPS3_MONTHLY.

Bader, J. and Latif, M. 2005. North Atlantic Oscillation response to anomalous Indian Ocean SST in a coupled GCM. J. Climate 18(24), 5382-5389.

Bakan, S., Jost, V. and Fennig, K. 2000. Satellite derived water balance climatology for the North Atlantic: first results. Phys. Chem. Earth Part B 25(2), 121-128.

Barnston, A. G. and Livezey, R. E. 1987. Classification, seasonality and persistence of low-frequency atmospheric circulation patterns. Mon. Wea. Rev. 115(6), 1083-1126.

Bentamy, A., Katsaros, K. B., Mestas-Nunez, A. M., Drennan, W. M., Forde, E. B. and co-authors. 2003. Satellite estimates of wind speed and latent heat flux over the global oceans. J. Climate 16(4), 637656.

Bojariu, R. and Reverdin, G. 2002. Large-scale variability modes of freshwater flux and precipitation over the Atlantic. Clim. Dyn. 18(5), 369-381.

Carleton, A. M. 1988. Meridional transport of eddy sensible heat in winters marked by extremes of the North Atlantic Oscillation, 1948/49-1979/80. J. Climate 1(2), 212-223.

Casey, K. S. 2004. Global AVHRR 4 km SST for 1985-2001, Pathfinder V5.0, NODC/RSMAS, Technical report, NOAA National Oceanographic Data Center, Silver Spring, Maryland. NODC Accession Numbers 0001763-0001864: Pathfinder AVHRR Version 5.0.

Cayan, D. R. 1992a. Latent and sensible heat flux anomalies over the northern oceans: driving the sea surface temperature. J. Phys. Oceanogr. 22(8), 859-881.

Cayan, D. R. 1992b. Latent and sensible heat flux anomalies over the Northern Oceans: the connection to monthly atmospheric circulation. J. Climate 5, 354-370.

Czaja, A. and Frankignoul, C. 1999. Influence of the North Atlantic SST on the atmospheric circulation. Geophys. Res. Lett. 26(19), 2969-2972.

Czaja, A. and Marshall, J. 2001. Observations of atmosphere-ocean coupling in the North Atlantic. Quart. J. Roy. Meteor. Soc. 127(576), 1893-1916.

Deser, C. and Blackmon, M. L. 1993. Surface climate variations over the North Atlantic Ocean\} during winter: 1900-1989. J. Climate 6(9), 1743-1753.

Dickson, R., Osborn, T., Hurrell, J., Meincke, J., Blindheim, J. and co-authors. 2000. The Arctic Ocean response to the North Atlantic Oscillation. J. Climate 13(15), 2671-2696.

Fairall, C. W., Bradley, E. F., Hare, J. E., Grachev, A. A. and Edson, J. B. 2003. Bulk parameterization of air-sea fluxes: updates and verification for the COARE algorithm. J. Climate 16(4), 571-591.
Fairall, C. W., Bradley, E. F., Rogers, D. P., Edson, J. B. and Young, G. S. 1996. Bulk parameterization of air-sea fluxes for Tropical OceanGlobal Atmosphere Coupled-Ocean Atmosphere Response Experiment. J. Geophys. Res.-Oceans 101, 3747-3764.

Greatbatch, R. 2000. The North Atlantic Oscillation. Stoch. Env. Res. Risk A. 14(4), 213-242.

Hoerling, M. P., Hurrell, J. W. and Xu, T. 2001. Tropical origins for recent North Atlantic climate change. Science 292(5514), 90-92.

Huang, J., Higuchi, K. and Shabbar, A. 1998. The relationship between the North Atlantic Oscillation and El Niño Southern Oscillation. Geophys. Res. Lett. 25(14), 2707-2710.

Hurrell, J. and van Loon, H. 1997. Decadal variations in climate associated with the North Atlantic Oscillation. Clim. Change 36(3), 301-326.

Hurrell, J. W. 1995a. Decadal trends in the North Atlantic Oscillation: regional temperatures and precipitation. Science 269(5224), 676-679.

Hurrell, J. W. 1995b. Transient eddy forcing of the rotational flow during northern winter. J. Atmos. Sci. 52(12), 2286-2301.

Hurrell, J. W., Kushnir, Y., Visbeck, M. and Ottersen, G. 2003. An overview of the North Atlantic Oscillation. In The North Atlantic Oscillation: Climate Significance and Environmental Impact. Vol. 134 (eds J. W. Hurrell, Y. Kushnir, G. Ottersen and M. Visbeck), Geophysical Monograph Series, pp. 1-35.

Jones, P., Jonsson, T. and Wheeler, D. 1997. Extension to the North Atlantic Oscillation using early instrumental pressure observations from Gibraltar and south-west Iceland. Int. J. Climatol. 17(13), 14331450.

Kanamitsu, M., Ebisuzaki, W., Woollen, J., Yang, S., Hnilo, J. and coauthors. 2002. NCEP-DOE AMIP-II Reanalysis (R-2). Bull. Amer. Meteor. Soc. 83(11), 1631-1643.

Klepp, C., Bumke, K., Bakan, S. and Bauer, P. 2010. Ground validation of oceanic snowfall in satellite climatologies during LOFZY. Tellus 62A. this issue.

Lott, J. N. 1994. The US summer of 1993: a sharp contrast in weather extremes. Weather 49(11), 370-383.

Mann, H. and Whitney, D. 1947. On a test of whether one of two random variables is stochastically larger than the other. Ann. Math. Stat. 18(1), $50-60$.

Mariotti, A. and Arkin, P. 2007. The North Atlantic Oscillation and oceanic precipitation variability. Clim. Dyn. 28(1), 35-51.

Marshall, J., Kushner, Y., Battisti, D., Chang, P., Czaja, A. and coauthors. 2001. North Atlantic climate variability: phenomena, impacts and mechanisms. Int. J. Climatol. 21(15), 1863-1898.

Miller, A. J., Zhou, S. and Yang, S. K. 2003. Relationship of the Arctic and Antarctic Oscillations to the outgoing longwave radiation. $J$. Climate 16(10), 1583-1592.

Murray, F. W. 1967. On the computation of saturation vapor pressure. J. Appl. Meteor. 6, 203-204.

NODC: 2008. National Oceanographic Data Center, Silver Spring, Maryland. URL: http://www.nodc.noaa.gov/sog/pathfinder4km/ userguide.html

Rogers, J. 1997. North Atlantic storm track variability and its association to the North Atlantic Oscillation and climate variability of northern Europe. J. Climate 10(7), 1635-1647.

Rogers, J. C. 1984. The Association between the North Atlantic Oscillation and the Southern Oscillation in the Northern Hemisphere. Mon. Wea. Rev. 112(10), 1999-2015. 
Romanova, V., Köhl, A., Stammer, D., Klepp, C., Andersson, A. and co-authors. 2010. Intercomparison of GECCO, HOAPS and NCEP net sea surface freshwater flux fields. Tellus 62A. this issue.

Rudolf, B., Hauschild, H., Rueth, W. and Schneider, U. 1994. Terrestrial precipitation analysis: operational method and required density of point measurements. In: Global Precipitations and Climate Change (eds M. Desbois and F. Desalmond), NATO ASI Series I, 26.

Schneider, U., Fuchs, T., Meyer-Christoffer, A. and Rudolf, B. 2008. Global precipitation analysis products of the GPCC, Internet publication, Global Precipitation Climatology Centre (GPCC), DWD. ftp://ftp.dwd.de/pub/data/gpcc/PDF/GPCC_intro_products_ 2008.pdf.

Serreze, M., Carse, F., Barry, R. and Rogers, J. 1997. Icelandic low cyclone activity: climatological features, linkages with the NAG, and relationships with recent changes in the Northern Hemisphere circulation. J. Climate 10(3), 453-464.

Sickmöller, M., Blender, R. and Fraedrich, K. 2000. Observed winter cyclone tracks in the Northern Hemisphere in re-analysed ECMWF data. Quart. J. Roy. Meteor. Soc. 126, 591-620.

Simmons, A., Uppala, S., Dee, D. and Kobayashi, S. 2007. ERA-Interim: new ECMWF reanalysis products from 1989 onwards. ECMWF Newslett. 110, 25-35.

Swift, C. T., Fedor, L. S. and Ramseier, R. O. 1985. An algorithm to measure sea ice concentration with microwave radiometers. J. Geophys. Res.-Oceans 90, 1087-1099.

Trenberth, K. E. 1984. Signal versus noise in the Southern Oscillation. Mon. Wea. Rev. 112(2), 326-332.
Trigo, R., Osborn, T. and Corte-Real, J. 2002. The North Atlantic Oscillation influence on Europe: climate impacts and associated physical mechanisms. Climate Res. 20(1), 9-17.

Uvo, C. 2003. Analysis and regionalization of northern European winter precipitation based on its relationship with the North Atlantic Oscillation. Int. J. Climatol. 23(10), 1185-1194.

Visbeck, M., Cullen, H., Krahmann, G. and Naik, N. 1998. An ocean model's response to North Atlantic Oscillation-like wind forcing. Geophys. Res. Lett. 25(24), 4521-4524.

Walker, G. 1923. Correlation in seasonal variations of weather. IX. A further study of world weather. Mem. Indian Meteorol. Dept. 24 (Part 9), 275-332.

Walker, G. and Bliss, E. 1932. World weather. Part V. Mem. Roy. Meteor. Soc. 4, 53-84.

Wallace, J. and Thompson, D. 2002. The Pacific center of action of the Northern Hemisphere annular mode: real or artifact? J. Climate 15(14), 1987-1991.

Walsh, J. and Portis, D. 1999. Variations of precipitation and evaporation over the North Atlantic Ocean, 1958-1997. J. Geophys. Res.-Atmos. 104, 16613-16631.

Wanner, H., Bronnimann, S., Casty, C., Gyalistras, D., Luterbacher, J. and co-authors. 2001. North Atlantic Oscillation-concepts and studies. Surv. Geophys. 22(4), 321-382.

Wilks, D. 2006. Statistical Methods in the Atmospheric Sciences 2nd Edition. Vol. 91 of International Geophysics Series, Academic Press Ltd, London, UK.

Xie, P. and Arkin, P. 1997. Global precipitation: a 17-year monthly analysis based on gauge observations, satellite estimates, and numerical model outputs. Bull. Amer. Meteor. Soc. 78(11), 2539-2558. 